\title{
Different Brain Circuitries Mediating Controllable and Uncontrollable Pain
}

\author{
Anne-Kathrin Bräscher, ${ }^{1,2 \star}$ (1)Susanne Becker, ${ }^{1,3 \star}$ Marie-Eve Hoeppli, ${ }^{1,5}$ and Petra Schweinhardt ${ }^{1,4,5}$ \\ ${ }^{1}$ Alan Edwards Centre for Research on Pain, Faculty of Dentistry, McGill University, Montreal, Quebec H3A 1G1, Canada, ${ }^{2}$ Department of Clinical \\ Psychology, Psychotherapy and Experimental Psychopathology, Johannes Gutenberg University Mainz, Mainz 55122, Germany, ${ }^{3}$ Department of Cognitive \\ and Clinical Neuroscience, Central Institute of Mental Health, Mannheim 68159, Germany, ${ }^{4}$ Department of Neurology and Neurosurgery, Faculty of \\ Medicine, McGill University, Montreal, Quebec H3A 2B4, Canada, and ${ }^{5}$ Faculty of Dentistry, McGill University, Montreal QC H3A 0C7, Canada
}

Uncontrollable, compared with controllable, painful stimulation can lead to increased pain perception and activation in pain-processing brain regions, but it is currently unknown which brain areas mediate this effect. When pain is controllable, the lateral prefrontal cortex (PFC) seems to inhibit pain processing, although it is unclear how this is achieved. Using fMRI in healthy volunteers, we examined brain activation during controllable and uncontrollable stimulation to answer these questions. In the controllable task, participants selfadjusted temperatures applied to their hand of pain or warm intensities to provoke a constant sensation. In the uncontrollable task, the temperature time courses of the controllable task were replayed (yoked control) and participants rated their sensation continuously. During controllable pain trials, participants significantly downregulated the temperature to keep their sensation constant. Despite receiving the identical nociceptive input, intensity ratings increased during the uncontrollable pain trials. This additional sensitization was mirrored in increased activation of pain-processing regions such as insula, anterior cingulate cortex, and thalamus. Further, increased connectivity between the anterior insula and medial PFC ( $\mathrm{MPFC})$ in the uncontrollable and increased negative connectivity between dorsolateral PFC (dlPFC) and insula in the controllable task were observed. This suggests a pain-facilitating role of the mPFC during uncontrollable pain and a pain-inhibiting role of the dlPFC during controllable pain, both exerting their respective effects via the anterior insula. These results elucidate neural mechanisms of context-dependent pain modulation and their relation to subjective perception.

Key words: controllability; dorsolateral prefrontal cortex (dlPFC); insula; medial prefrontal cortex (mPFC); pain; pain modulation

\section{Significance Statement}

Pain control is of uttermost importance and stimulus controllability is an important way to achieve endogenous pain modulation. Here, we show differential effects of controllability and uncontrollability on pain perception and cerebral pain processing. When pain was controllable, the dorsolateral prefrontal cortex downregulated pain-evoked activation in important pain-processing regions. In contrast, sensitization during uncontrollable pain was mediated by increased connectivity of the medial prefrontal cortex with the anterior insula and other pain-processing regions. These novel insights into cerebral pain modulation by stimulus controllability have the potential to improve treatment approaches in pain patients.

\section{Introduction}

Would you rather remove a splinter from your finger yourself or let somebody else do it? Many people would choose the former,

Received May 20, 2015; revised March 14, 2016; accepted March 17, 2016.

Author contributions: A.-K.B., S.B., and P.S. designed research; A.-K.B. and S.B. performed research; M.-E.H. contributed unpublished reagents/analytic tools; A.-K.B. and S.B. analyzed data; A.-K.B., S.B., and P.S. wrote the paper.

This work was supported by the Canadian Institutes of Health Research (Operating Grant to P.S.). A.-K.B. was supported by a scholarship from the German National Academic Foundation. S.B. was supported by an International Association for the Study of Pain International Trainee Fellowship funded by the Scan|Design Foundation BY INGER \& JENS BRUUN. We thank Tor Wager for help with the NPS analysis.

The authors declare no competing financial interests. illustrating the empowerment of having control over pain (Bowers, 1968). The clinical relevance of pain controllability has been shown for acute (Tinti et al., 2011) as well as chronic pain (Härkäpää et al., 1991; Jensen and Karoly, 1991) and experimental work confirms that controllable pain stimuli are perceived as less intense than uncontrollable stimuli (Arntz and Schmidt,

\footnotetext{
${ }^{*}$ A. - K.B. and S.B. contributed equally to this work.

Correspondence should be addressed to Anne-Kathrin Bräscher, Department of Clinical Psychology, Psychotherapy and Experimental Psychopathology, Johannes Gutenberg University Mainz, Wallstra $\beta$ e 3, Mainz 55122, Germany. E-mail: abraesch@uni-mainz.de.

DOI:10.1523/JNEUROSCI.1954-15.2016

Copyright $\odot 2016$ the authors $\quad 0270-6474 / 16 / 365013-13 \$ 15.00 / 0$
} 
1989; Müller, 2011). Imaging studies have extended these findings by demonstrating that activity in pain-processing brain regions, including the anterior cingulate cortex (ACC), insula, thalamus, primary and secondary somatosensory cortex (SI, SII), as well as in pain-modulatory regions such as the amygdala, periaqueductal gray (PAG), and the prefrontal cortex (PFC) varies with pain stimulation being controllable or uncontrollable (Salomons et al., 2004; Mohr et al., 2005; Helmchen et al., 2006; Wiech et al., 2006; Salomons et al., 2007). Human and animal studies point to an important role of the lateral PFC, particularly the anterior and dorsolateral PFC (dlPFC), in mediating the pain-inhibitory effects of (perceived) control over pain (Amat et al., 2005; Wiech et al., 2006; Borckardt et al., 2011), predominantly in individuals who do not believe that the outcomes of their behavior is determined by their decisions and efforts (i.e., who have low internal control beliefs; Wiech et al., 2006). However, it is currently unclear how the lateral PFC affects painprocessing regions to achieve pain inhibition when pain is controllable. In addition, although implicitly assumed in previous studies, it is has not been shown whether uncontrollability facilitates pain processing and, if so, which brain areas might drive pain facilitation by uncontrollability. Candidate regions for such a facilitation are the pain-modulatory regions medial PFC (mPFC), amygdala, and PAG, which show increased activation when pain is uncontrollable (Salomons et al., 2004; Mohr et al., 2005; Wiech et al., 2006). The mPFC, including the cingulofrontal cortex, is a pain-modulatory area that has been shown to facilitate pain in different contexts (Ploghaus et al., 2001; Mayer et al., 2005; Schweinhardt et al., 2008; Berna et al., 2010). The PAG plays an important role in descending pain-modulatory pathways, including facilitation (Porreca et al., 2002; Gwilym et al., 2009; Yoshida et al., 2013). Finally, the amygdala plays a key role in fear and threat processing, also in the context of pain (Neugebauer et al., 2004; Phelps and LeDoux, 2005), and can be considered a candidate region because it has been hypothesized that a lack of control increases the threatening value of pain (Bowers, 1968; Arntz and Schmidt, 1989).

Here, we tested in healthy volunteers in an fMRI) experiment whether uncontrollability of pain stimuli facilitates pain perception and if such facilitation is reflected by increased activation in pain-processing regions such as insula, thalamus, ACC, SI, and SII. Univariate analysis and comparison with a multivariate cerebral pattern of pain described previously (Wager et al., 2013) were used to test whether uncontrollable pain is associated with more activation in pain-processing regions than controllable pain. We also investigated whether the functional connectivity of an important pain-processing region, the insula, with $\mathrm{mPFC}$, amygdala, or PAG is increased during uncontrollability and whether the insula is inversely connected to the lateral PFC during controllability, indicating potentially downregulation.

\section{Materials and Methods}

\section{Subjects}

Inclusion criteria included age between 18 and 40 years and good health. Exclusion criteria were the presence or history of significant neurological or psychiatric disease, chronic pain, any significant medical condition or sleep disorders; regular consumption of alcohol or recreational drugs; recent use of any pain medication; or regular or frequent night shift work. The study was approved by the local ethics committee and written informed consent was obtained from all subjects. Subjects were compensated with $\$ 50$ US for their participation.

Three subjects were excluded because they did not rate the painful stimulus as painful during $>50 \%$ of the pain trials. The final sample consisted of 23 volunteers (13 males; 1 left-handed) age 19-30 years (mean $24.2 \pm 3.57$ years).

\section{Experimental design}

The study followed a within-subject yoked-control design with two within-subjects factors with two levels each (task "controllable" vs "uncontrollable" and stimulation intensity "pain" vs "warm"). Warm intensities were used to identify pain-specific effects in the behavioral responses and brain activation. The sequence of stimulation intensities was pseudorandomized with the same order across participants. In each functional scan, the first 12 trials were controllable, followed by 12 uncontrollable trials to avoid frequent switching between the two tasks so that subjects would not be confused which task was to be performed in a specific trial (Fig. 1). Because of the yoked design, uncontrollable trials had to be preceded by controllable trials (see below). In the controllable task, subjects performed a temperature regulation task (Kleinböhl et al., 1999; Hölzl et al., 2005; Becker et al., 2011). After the thermode had reached the target temperature, the subject had to keep his/her sensation constant by antagonizing any perceived temperature change using a response unit. Therefore, subjects had full instrumental control (Miller, 1979) over the physical stimulus intensity. The response unit allowed regulating the temperature down or up with a left or right button, respectively. If the sensation had not changed, subjects had to press a middle button to control for motor responses. Because the temperature only changed when the subject regulated it, any change perceived by the subject was due to sensitization or habituation. A flashing arrow displayed on a screen visible to the subject reflected the subject's response and served as visual feedback to minimize unspecific differences to the uncontrollable task. After $20 \mathrm{~s}$, the temperature returned to baseline. In the uncontrollable task, the temperature profiles of the previous controllable trials were replayed unbeknownst to the subject. Now, the subject rated his or her sensation on a visual analog scale (VAS; see below) projected onto the screen. The right mouse button increased the rating; the left mouse button decreased the rating. If the sensation had not changed, the subject had to press the middle mouse button. Due to the yoked design, the nociceptive input was identical in both tasks.

During both tasks, a green square flashed every $2 \mathrm{~s}$, prompting the subject to give a response. The intertrial interval was $20 \mathrm{~s}$.

\section{General procedure}

Each subject underwent two sessions: a familiarization session and an fMRI session, 1-3 d apart.

\section{Familiarization session}

The study was explained to the subject and, after obtaining informed consent, participants were familiarized with the stimuli, the tasks, and the rating scales. Cutaneous heat stimuli were delivered using a $30 \times 30$ $\mathrm{mm}^{2}$ contact thermode (Pathway; Medoc Advanced Medical Systems). Stimulus intensities were individually determined (see below), but temperatures $>50^{\circ} \mathrm{C}$ were not allowed for safety reasons. A vertically oriented VAS anchored with 0 ("no sensation"), 40 ("just painful," defined as the pain threshold), and 100 ("most intense pain tolerable") was used to rate nonpainful and painful sensations. This VAS has been shown to possess linear properties (Lautenbacher et al., 1992). Pain tolerance testing was performed so that the subjects experienced a sensation that corresponded to the upper end of the VAS, thereby providing a perceptual anchor. For this, the thermode was applied to the subject's forearm and the temperature slowly increased (rise rate $0.5^{\circ} \mathrm{C} / \mathrm{s}$ ) from $32^{\circ} \mathrm{C}$ until the subject stopped it by pressing a button on the response unit when the sensation became intolerable. This procedure was repeated twice with a rise rate of $1.5^{\circ} \mathrm{C} / \mathrm{s}$.

To assess subjects' pain threshold, a series of stimuli was applied to the testing site to be used during the fMRI: the subject's nondominant thenar eminence. After each stimulus, the subject indicated their most intense sensation during the stimulation on the VAS. The baseline temperature was $36^{\circ} \mathrm{C}$ and the first target temperature was $39^{\circ} \mathrm{C}$ (stimulus duration $5 \mathrm{~s}$ ). The subsequent target temperatures each increased by $1^{\circ} \mathrm{C}$ until the participant rated a stimulus as "just painful." Based on this temperature, 5 more temperatures around this initial painful temperature $\left(-1^{\circ} \mathrm{C}\right.$, $\left.+0.5^{\circ} \mathrm{C},+/-0^{\circ} \mathrm{C},+1^{\circ} \mathrm{C},-0.5^{\circ} \mathrm{C}\right)$ were applied and the one closest to the 


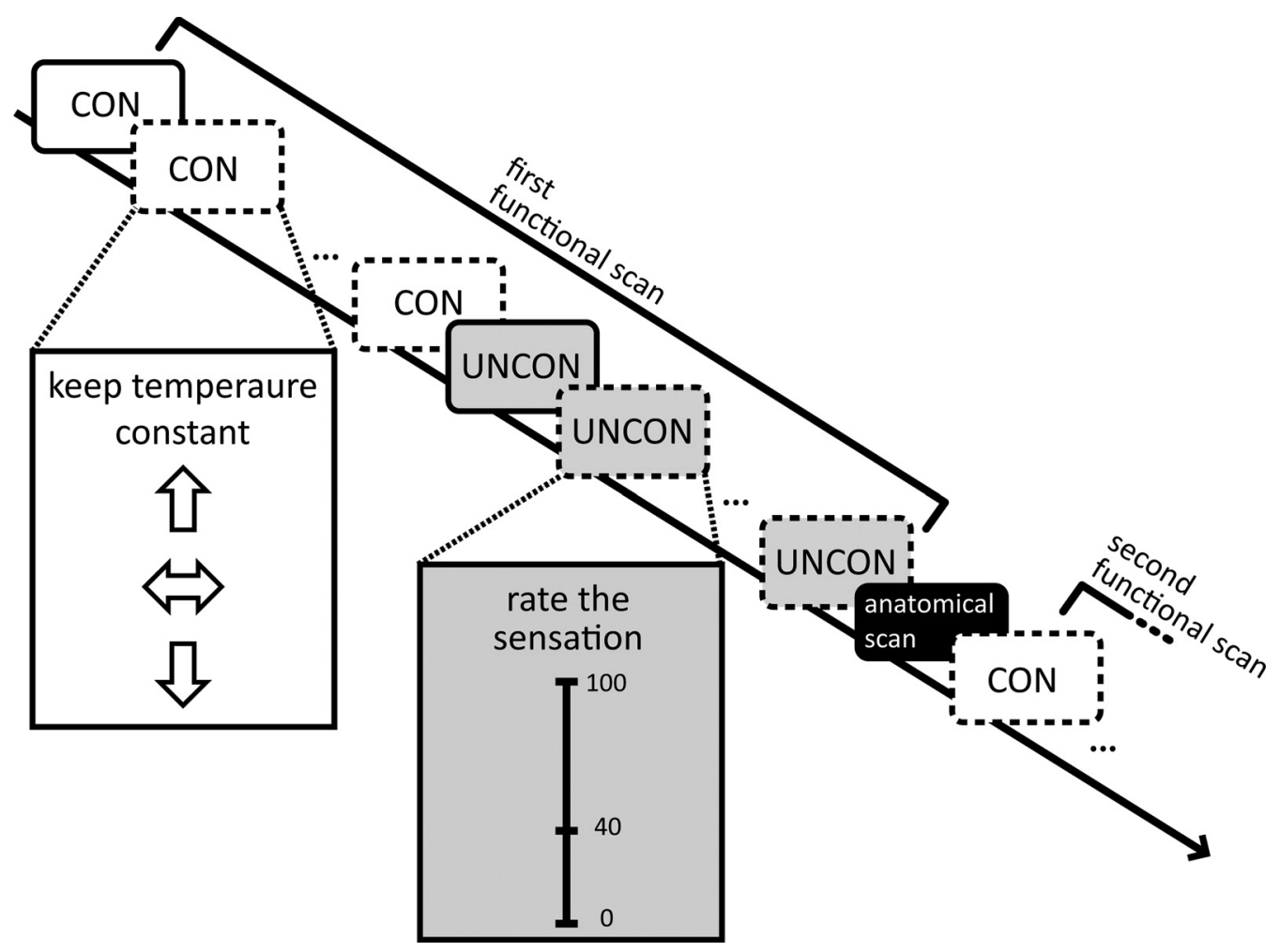

Figure 1. Experimental procedure. Twelve controllable trials (CON) were followed by 12 uncontrollable trials (UNCON) during the first functional scan. Participants saw instructions for the respective trials and visual feedback of their responses on a screen, indicated here by the insets. After an anatomical scan (10 min), a second functional scan was performed during which 12 controllable trials were again followed by 12 uncontrollable trials. The sequence of stimulation intensities (painful, solid line; warm, dashed line) was pseudorandomized.

"just painful" anchor was used as an estimate of the pain threshold. The resulting average pain threshold was $44.2^{\circ} \mathrm{C}\left(\mathrm{SD}=1.42^{\circ} \mathrm{C}\right)$, consistent with the literature (Rolke et al., 2006).

The temperature to be used as initial temperature in the controllable pain trials was the temperature of the individual's pain threshold plus $1.5^{\circ} \mathrm{C}$. Adjustments were made if this temperature was not rated as moderately painful or did not fall between $45.5^{\circ} \mathrm{C}$ and $48^{\circ} \mathrm{C}$ (mean temperature $=47^{\circ} \mathrm{C}, \mathrm{SD}=0.78^{\circ} \mathrm{C}$ ). For the controllable warm trials, the initial temperature was $39^{\circ} \mathrm{C}$ or $40^{\circ} \mathrm{C}$, depending on the participant's rating (mean temperature $=39.5^{\circ} \mathrm{C}, \mathrm{SD}=0.5^{\circ} \mathrm{C}$ ).

\section{FMRI session}

At the beginning of the fMRI session, subjects were reminded of the tasks and stimulus intensities were adjusted if necessary to achieve moderately painful and warm sensations. FMRI data acquisition was performed in two functional scans separated by an anatomical scan (Fig. 1).

Stimulus presentation was controlled by a laptop computer using Eprime software (Psychology Software Tools). The display was backprojected onto a screen and was visible via a mirror that was mounted on the head coil of the MRI scanner. A computer mouse with three buttons, modified in-house to ensure MR compatibility, served as response unit so that the subjects could perform the experimental tasks.

\section{Questionnaires}

The internal-external control (IPC) scale (Levenson, 1981) was used to identify the locus of control beliefs (subscales: "internal," "powerful others," and "chance"). Twenty subjects completed this questionnaire. All subjects completed the State-Trait Anxiety Inventory (Spielberger et al., 1970) indicating their level of state anxiety before the scan and their level of trait anxiety after the scan.

\section{FMRI data acquisition}

Imaging data were acquired on a 3 T Siemens TRIO MRI scanner at the McConnell Brain Imaging Center, Montreal Neurological Institute (MNI), using a 32-channel head coil. A gradient echo planar imaging (EPI) sequence covering the whole brain was used for functional scans
$[\mathrm{TR}=2.62 \mathrm{~s}, \mathrm{TE}=30 \mathrm{~ms}$, flip angle $=90$ degree, 44 interleaved, $3.5 \mathrm{~mm}$ thick axial slices (parallel to the AC-PC line), field of view (FoV) 224 $\mathrm{mm} \times 224 \mathrm{~mm}$, matrix $64 \times 64$, resulting in an in-plane resolution of $3.5 \times 3.5 \mathrm{~mm}^{2}, 441$ image volumes]. The first two images were discarded to allow steady-state magnetization. Field maps were obtained using a gradient echo sequence $(\mathrm{TE}=20 \mathrm{~ms}, 0.47 \mathrm{~ms}$ dwell time, FoV and matrix identical to EPI). High-resolution, anatomical T1-weighted images (RF spoiled, prescan normalized MPRAGE sequence, $\mathrm{TR}=2300 \mathrm{~ms}$, TE $=$ $2.98 \mathrm{~ms}$, TI $=900 \mathrm{~ms}$, flip angle $=9$ degree, FoV $192 \mathrm{~mm} \times 256 \mathrm{~mm} \times$ $256 \mathrm{~mm}$, matrix $192 \times 256 \times 256$, resulting in a voxel size of $1 \mathrm{~mm}^{3}$ ) were acquired for all subjects for coregistration purposes.

\section{Statistical analysis of behavioral data}

Mean values and SDs were calculated for the self-adjusted temperature changes and intensity ratings. Two-sided $t$ tests were used to test whether the temperatures or VAS ratings at the end of the trial differed from those at the beginning of the trial. A linear mixed model was used to test whether VAS ratings changed over the course of the experiment. IPC scores and anxiety scores were correlated with the psychophysical data using Pearson's correlations (uncorrected for multiple comparisons). Alpha $=0.05$ was used as the significance level. Statistical tests were performed with PASW Statistics 17.0.3.

\section{Statistical analysis of $F M R I$ data}

All image processing and statistical analysis was performed using the software package FSL 5.0.8 (FMRIB's Software Library; Smith et al., 2004). Of 1104 trials in total, 19 trials were excluded due to missing data caused by technical problems such as thermode malfunction. Eleven uncontrollable trials were shortened due to technical failure.

Subject-level analysis. To eliminate scanner artifacts, denoising was performed on the raw images, before preprocessing, using MELODIC (Multivariate Exploratory Linear Optimized Decomposition into Independent Components; Beckmann and Smith, 2004) within FEAT (FMRI Expert Analysis Tool). The number of independent components was estimated from the data. Components were individually inspected and 

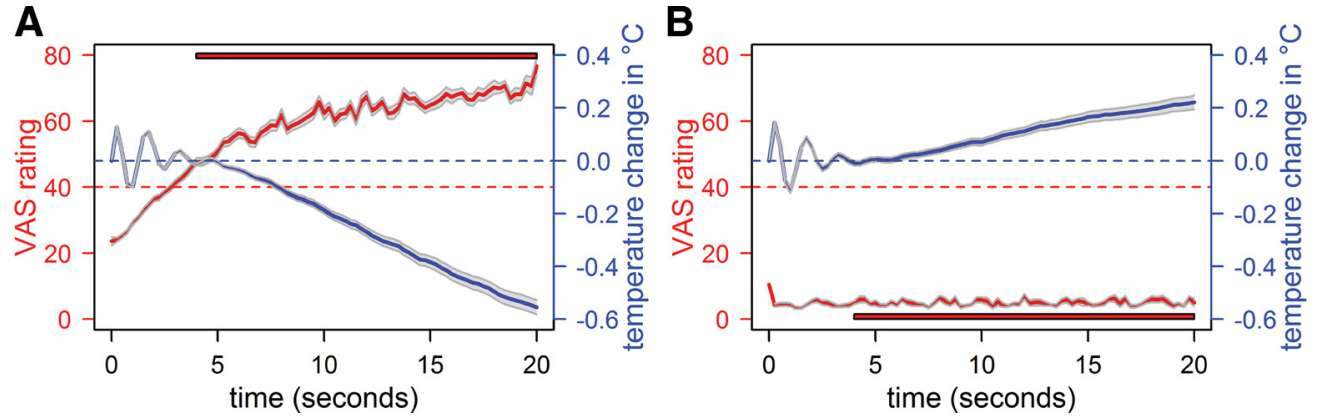

Figure 2. Psychophysical data of painful $(\boldsymbol{A})$ and warm $(\boldsymbol{B})$ trials. Illustrated are the temperature courses in blue, averaged across trials and participants, and the VAS ratings, equally averaged across trials and participants, in red. For better illustration, we downsampled the displayed data (interval length $=250 \mathrm{~ms}$ ) and do not display the temperature rise in the beginning of the trial; that is, illustrated are the $20 \mathrm{~s}$ after reaching the target temperature. Gray ribbons represent the SEM. Because increasing ratings at the beginning of the uncontrollable trials do not reflect sensitization (the subjects needed time to adjust their rating after the thermode had reached the target temperature), the first $4 \mathrm{~s}$ of the uncontrollable trials were excluded. The red bars indicate the time segment that was included in the comparison of intensity ratings between end and beginning of the trial, as well as as pain-rating regressors in the fMRl analysis of the uncontrollable trials (see Materials and Methods). The red dotted line depicts the "just painful" anchor of the VAS. The blue dotted line marks habituation (values $>0$ ) and sensitization behavior (values $<0$ ) for the controllable trials. The initial variations in temperature were due to fluctuations of the thermode.

removed using regression if the spatial map or the associated time series was clearly abnormal, such as the spatial map being striped or the time series showing spikes $>5$ SDs. Then, the following preprocessing steps were applied to each functional dataset: spatial smoothing (Gaussian kernel, full width at half-maximum: $5 \mathrm{~mm}$ ), motion correction, and temporal high-pass filtering (Gaussian-weighted least-squares straight line fitting with $\sigma=100 \mathrm{~s}$ ). Susceptibility-related distortions were corrected using FSL field map correction routines.

The time courses of CSF and white matter masks were extracted to be used as nuisance variables. To generate CSF and white matter masks, the individual structural images were segmented into CSF, white matter, and gray matter using FAST (Zhang et al., 2001), thresholded at 0.8 (Biswal et al., 2010). CSF and white matter masks were transformed into functional space by applying the inverse transformation matrix of the individual motion-corrected EPI to the structural image using FLIRT. The masks were rebinarized and partial volumes edges excluded after interpolation. Finally, the time series averaged across the voxels of the respective mask was extracted.

A general linear model (GLM) was applied to each functional dataset with the following regressors of interest: four condition regressors (controllable pain, controllable warm, uncontrollable pain, uncontrollable warm), the time-rating curves (i.e., the time courses of the intensity ratings) of uncontrollable trials, and time-temperature curves of controllable trials (excluding the stimulus rise time; time bins of $2000 \mathrm{~ms}$ ). Temperature rise and fall times, motion outliers, time series for CSF and white matter, and time-temperature curves in the uncontrollable conditions were included in the model as nuisance variables. In addition, the first $4 \mathrm{~s}$ of the $20 \mathrm{~s}$ stimulation period were modeled as nuisance regressors to account for the time subjects needed to "catch up" with their VAS ratings with the initial temperature increase of the thermode in the uncontrollable task (Fig. 2). Regressors were convolved with a gamma hemodynamic response function and the first temporal derivatives were included. This model allowed identifying the main effects and interaction of task (controllable or uncontrollable) and stimulation intensity (pain or warm), as well as brain activation correlating with sensitization or habituation in the respective tasks (i.e., with self-adjusted temperature changes in the controllable tasks and with subjective ratings in the uncontrollable tasks).

Voxelwise parameter estimates were derived using the appropriate contrasts. Individual's functional images were registered to their own structural scan using linear transformation (FLIRT; Jenkinson et al., 2002), followed by registration to the International Consortium for Brain Mapping (ICBM) 152 nonlinear sixth-generation symmetric template in MNI standard space using nonlinear transformations (FNIRT, warp resolution $=10 \mathrm{~mm}$ ). The parameter estimates and the corresponding estimates of the variance from the two functional scans of each subject were merged in a second-level fixed-effects analysis.
Group level analysis. Third-level analyses were performed using a mixed-effects model implemented in FLAME (Beckmann et al., 2003). Statistical inference was based on a voxel-based threshold of $Z=2.3$ cluster corrected across the whole brain at $p<0.05$.

Neurological Pain Signature. We tested the correspondence of the different stimulation intensities and tasks with the so-called "Neurological Pain Signature" (NPS; Wager et al., 2013), which was provided by its authors. The NPS is a distributed pattern of fMRI activations defined by multivariate pattern analysis, which sensitively and specifically tracks changes in perceived pain intensity achieved by altering nociceptive input (Wager et al., 2013). The rationale for testing any modulatory influences on the NPS was its high sensitivity and the fact that it does not correspond to nonpainful emotional events that otherwise activate similar brain areas. Modulation of the NPS by un/controllability would be consistent with the interpretation that pain facilitation by uncontrollability occurs in pain intensity coding regions. Lack of effects on the NPS, in conjunction with no change in the magnitude of pain-related activation in the univariate GLM analysis, would point to un/controllabilityinduced pain modulation by other cerebral systems.

For calculating the strength of expression of the NPS response in the different conditions, the a priori defined pattern of regression weights for each voxel (Wager et al., 2013) was used to calculate the scalar product with the brain activation maps (maps of parameter estimates obtained from the subject-level fMRI analysis) of each contrast of interest (controllable pain, uncontrollable pain, controllable warm, uncontrollable warm, the time-rating curves of uncontrollable trials, and the timetemperature curves of controllable trials), resulting in one scalar value for each subject for each contrast. These values were analyzed for differences with a repeated-measuremes ANOVA design using mixed-model procedures with the factors "stimulation intensity" (pain or warm), "task" (controllable or uncontrollable), and "regressor type" (i.e., constant regressors coding the four conditions and the time-rating/time-temperature regressors).

Connectivity analyses. To investigate the connectivity between pain processing and potential pain-modulatory brain regions, depending on un/controllability, psychophysiological interaction analyses (PPIs; Friston et al., 1997) were performed. PPI analyses provide a model of how a psychological context (i.e., uncontrollability) changes the influence of one area on another area and is regarded as a measure of effective connectivity (Friston et al., 1997). The anterior insula served as seed region because it is a core region implicated in pain processing (Apkarian et al., 2005 ) and is consistently modulated by psychological interventions including controllability (Salomons et al., 2004; Wiech et al., 2006). For the seed, an ellipsoid was created that comprised the peak coordinates for the contrasts associated with significant insula activation (controllable pain, uncontrollable pain, controllable warm, uncontrollable warm, time-rating curve of uncontrollable pain). Four PPI regressors were computed, 
each as the scalar product of the time series of the activity averaged across the voxels in the anterior insula seed and a vector coding for the controllable pain, uncontrollable pain, controllable warm, and uncontrollable warm conditions, respectively. All PPI regressors were included in the same GLM to model the full space of the conditions of interest for this analysis. Commonly, two conditions are subtracted from each other and modeled as one PPI regressor. However, such an approach makes assumptions about the interrelationship between the conditions and does not allow comparisons of similarities between the PPI contrasts. Evidence demonstrates also a better single-subject model fit and higher sensitivity for true positive findings when modeling the full space of conditions (McLaren et al., 2012). In addition to the PPI regressors, regressors coding all four conditions (controllable painful, controllable warm, uncontrollable painful, uncontrollable warm), the average time course extracted from the seed, and the same nuisance variables as in the GLM were included to ensure that the variance explained by the PPI regressors was not confounded by main effects of the conditions or other factors (O'Reilly et al., 2012). Therefore, variance explained by the PPI regressors represents specifically variance explained over and above the variance explained by the conditions, the time series, and error variance explained by the nuisance regressors, indicating which brain regions are functionally connected to the seed dependent on the experimental condition. The regions of interest (ROIs) were the lateral PFC (controllable task) and the mPFC, amygdala, and PAG (uncontrollable task). To test the specificity of the effects, the PPI analyses were repeated with the lateral PFC serving as ROIs for the uncontrollable tasks and the mPFC, amygdala, and PAG serving as ROIs for the controllable tasks. Lateral PFC was defined as Brodmann areas 9, 10, and 46. The amygdalae were defined with the Harvard-Oxford Subcortical Structural Atlas implemented in FSL (signal intensity minimum at 20\%). The ROI for the PAG was manually drawn on the ICBM 152 template and comprised 112 voxels. The ROI for mPFC was generated by combining the cingulate cortex, paracingulate cortex, frontal medial cortex, frontal pole, and subcallosal cortex as defined in the Harvard-Oxford Cortical Structural Atlas implemented in FSL. The resulting area was restricted in the $\mathrm{x}$ dimension by planes at $x=-16$ and $x=16$ and in the $y$ dimension by a plane extending from the vertical ramus of the Sylvian fissure ( $y=20$; Kates et al., 2002) to obtain the final mPFC ROI. Statistical inference was based on a voxel-based threshold of $Z=2.3$ cluster corrected across the ROIs at $p<0.05$.

Regions that were identified in the PPI as pain-modulatory areas were used as seeds in a "reversed" PPI analysis. This was done to test whether pain-processing brain regions other than anterior insula showed increased connectivity to the regions identified in the first PPI (i.e., dlPFC for the controllable pain and controllable warm conditions, two clusters in $\mathrm{mPFC}$ for the uncontrollable pain condition and one cluster in mPFC for the uncontrollable warm condition). For the "reversed" PPI analyses, a mask of pain-processing brain regions served as ROIs (composed of bilateral insula, SI, SII, thalamus, and ACC derived from the Harvard-Oxford Cortical Structural Atlas and HarvardOxford Subcortical Structural Atlas implemented in FSL) and statistical inference was based on a voxel-based threshold of $Z=2.3$ cluster corrected across the mask at $p<0.05$.

Localization of activation was achieved by inspection of group activation maps overlaid on the nonlinear ICBM-152 template. Images are displayed in radiological convention; that is, the right side of the brain is on the left. Coordinates are given in MNI space.

Additional analyses. Several additional analyses were performed, mainly for control purposes. A GLM containing only the four condition regressors (controllable pain, uncontrollable pain, controllable warm, uncontrollable warm) and the nuisance variables was performed to confirm the main effects of condition.

To test the specificity of brain activation associated with additional sensitization in the uncontrollable pain condition, a "control GLM" was performed using the pain ratings recorded during the uncontrollable trials as additional regressor for the controllable pain condition. The other regressors and nuisance variables were the same as in the original GLM.

In the uncontrollable pain condition, subjects pressed the button more frequently than at every cue, reflecting the increased sensitization in this condition. We therefore repeated the GLM analysis as well as the PPI analyses with an additional regressor of no interest coding the button presses. This analysis is not ideal because the variance cannot be unambiguously explained due to multicollinearity of the button press regressor with the time-intensity and time-temperature curves. It was nevertheless performed to gain insight into the potential confound caused by the button presses.

Last, the modeled time courses of signal change were extracted for all contrasts with significant anterior insula activation; $5 \mathrm{~mm}$ spheres were created around the anterior insula peaks of the significant contrasts and the time courses of the percentage signal change extracted.

\section{Results}

\section{Behavioral data}

In the controllable task during painful trials, subjects regulated the temperature down to keep their sensation constant (Fig. 2A), which indicates that sensitization (as a specific form of pain facilitation) occurred over the course of the 20-s-long trials (temperature difference between end and beginning of the trial: $\mathrm{M}=$ $\left.-0.7^{\circ} \mathrm{C}, \mathrm{SD}=0.398^{\circ} \mathrm{C} ; \mathrm{T}=8.41, p<0.001\right)$. During warm trials, subjects on average increased the temperature; that is, they habituated to the stimulation $\left(\mathrm{M}=0.19^{\circ} \mathrm{C}, \mathrm{SD}=0.305^{\circ} \mathrm{C} ; \mathrm{T}=-3.00\right.$, $p=0.007$; Fig. $2 B$ ).

In the uncontrollable task, subjects received the identical nociceptive input as in the controllable task by being administered the self-adjusted temperature time courses of the controllable trials. Consistent with the notion that uncontrollability facilitates pain, they rated the sensation as continuously getting more painful during pain trials (rating difference between end and beginning of trial: $\mathrm{M}=23.2, \mathrm{SD}=9.22, \mathrm{~T}=10.95, p<0.001$; Fig. $2 A$ ), although they had regulated the temperature time courses to produce constant sensations in the controllable task. During warm trials, the ratings remained stable throughout the trial $(\mathrm{M}=0.38$, $\mathrm{SD}=1.06, \mathrm{~T}=0.51, p=0.62$; Fig. $2 B$ ) and thus matched the perceived sensation in the controllable task, indicating that subjects were able to perform the temperature regulation task. These results indicate that the effects of uncontrollability on the perception of thermal stimuli are specific for painful sensations.

Although the yoked design required that the uncontrollable trials were presented after the controllable trials, sensitization over the course of the experiment can be ruled out as an alternative explanation for the increasing pain ratings in the uncontrollable trials because pain ratings did not increase across trials (mixed-model analysis, interaction effect trial $\times$ intensity: $\left.F_{(5,514)}=0.7, p=0.626\right)$.

\section{Locus of control and anxiety scores}

The magnitude of self-regulated temperature changes in the controllable painful condition correlated positively with the "powerful others" subscale of the IPC locus of control scale $(r=0.59, p=0.012)$. The more a subject believed that his/her life was controlled by others, the more he/she sensitized in response to the painful stimulation. Neither trait $(\mathrm{M}=36.4, \mathrm{SD}=$ $9.74)$ nor state anxiety scores $(\mathrm{M}=29.1, \mathrm{SD}=8.07)$ correlated with the self-regulated temperature in the controllable task or the subjective ratings in the uncontrollable task (all $p$-values $>0.4$ ).

\section{Pain-related brain activation}

The uncontrollable pain and controllable pain conditions (Fig. $3 A$ ) revealed largely overlapping activations of typical painprocessing brain regions (i.e., regions commonly activated during experimental heat in fMRI studies in healthy volunteers; Apkarian et al., 2005; Farrell et al., 2005), including bilateral insula, thalamus, SII, ACC, PFC, premotor cortex, cerebellum, and 

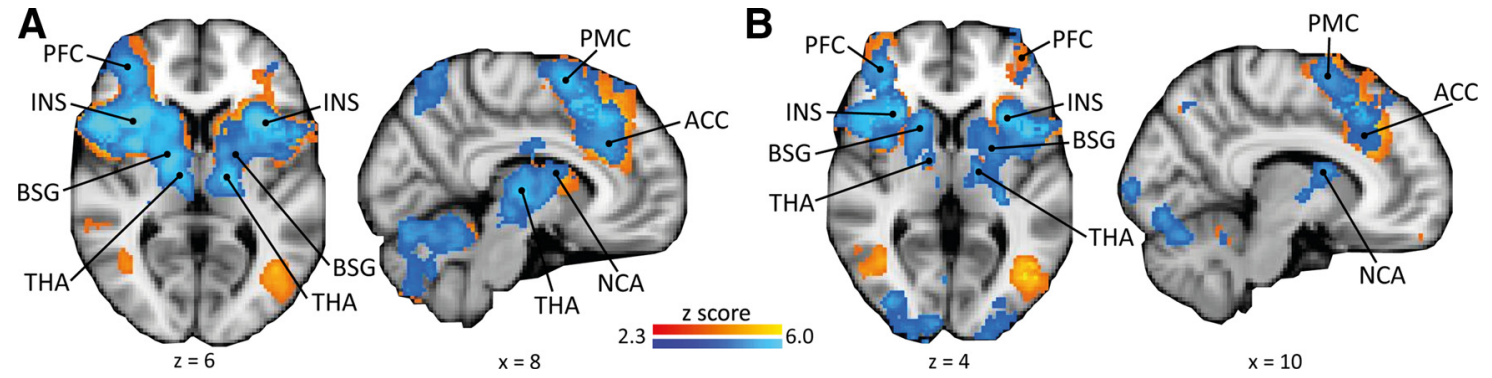

Figure 3. Pain-related brain responses. Shown are uncontrollable pain ( $\boldsymbol{A}$, blue) and controllable pain ( $\boldsymbol{A}$, red) and uncontrollable warm $(\boldsymbol{B}$, blue) and controllable warm $(\boldsymbol{B}$, red) conditions of the GLM analysis (main effects). INS, Insula; BSG, basal ganglia; THA, thalamus; NCA, nucleus caudatus; PFC, prefrontal cortex; PMC, premotor cortex.

Table 1. Brain responses to pain versus warm stimulation for the uncontrollable and controllable tasks

\begin{tabular}{|c|c|c|c|c|c|}
\hline \multirow[b]{2}{*}{ Brain region } & \multirow{2}{*}{$\begin{array}{l}\text { Cluster size } \\
\text { (no. of voxels) }\end{array}$} & \multirow{2}{*}{$\begin{array}{l}\text { Z-score } \\
\text { peak }\end{array}$} & \multicolumn{3}{|c|}{ MNI peak coordinates $(\mathrm{mm})$} \\
\hline & & & $x$ & $y$ & $z$ \\
\hline \multicolumn{6}{|l|}{ Uncontrollable condition } \\
\hline Cluster spanning & 27081 & 6.49 & -28 & -66 & -28 \\
\hline \multirow{2}{*}{ Cerebellum } & & 6.49 & -28 & -66 & -28 \\
\hline & & 4.60 & 24 & -58 & -28 \\
\hline $\begin{array}{l}\text { Central opercular } \\
\text { cortex }\end{array}$ & & 6.16 & 38 & 8 & 8 \\
\hline \multirow[t]{2}{*}{ Thalamus } & & 6.12 & 14 & -20 & 10 \\
\hline & & 5.95 & -18 & -20 & 14 \\
\hline $\mathrm{ACC}$ & & 3.59 & 6 & 20 & 30 \\
\hline \multirow[t]{2}{*}{ Insula } & & 5.91 & 36 & 14 & 6 \\
\hline & & 5.04 & -32 & 16 & 4 \\
\hline SII & & 4.78 & 56 & -20 & 22 \\
\hline Cluster spanning & 3241 & 5.19 & -36 & -10 & 64 \\
\hline \multirow{3}{*}{$\begin{array}{l}\text { SMA/premotor } \\
\text { cortex }\end{array}$} & & 5.19 & -36 & -10 & 64 \\
\hline & & & & & \\
\hline & & 5.52 & 22 & -2 & 54 \\
\hline $\mathrm{SI}$ & & 4.07 & -42 & -36 & 54 \\
\hline MI & & 4.06 & -36 & -26 & 56 \\
\hline Cluster spanning & 693 & 4.31 & 16 & -64 & 42 \\
\hline Precuneus & & 4.31 & 16 & -64 & 42 \\
\hline Superior parietal & & 3.97 & 10 & -62 & 60 \\
\hline \multicolumn{6}{|l|}{ cortex } \\
\hline \multirow{2}{*}{\multicolumn{3}{|c|}{ Controllable condition }} & -16 & & 58 \\
\hline $\begin{array}{l}\text { Controllable condition } \\
\text { Cluster spanning }\end{array}$ & & 6.59 & 42 & -12 & 14 \\
\hline SII & 23104 & 6.59 & 42 & -12 & 14 \\
\hline \multirow[t]{2}{*}{ Insula } & & 6.32 & 38 & -14 & 16 \\
\hline & & 5.41 & -38 & 12 & -4 \\
\hline $\begin{array}{l}\text { Central opercular } \\
\text { cortex }\end{array}$ & & 6.25 & 56 & 0 & 4 \\
\hline ACC & & 4.54 & 4 & 12 & 44 \\
\hline \multirow[t]{2}{*}{ Thalamus } & & 5.50 & 12 & -6 & 6 \\
\hline & & 5.41 & -14 & -18 & 16 \\
\hline SMA & & 4.12 & 6 & 18 & 60 \\
\hline Cerebellum & & 5.26 & -26 & -62 & -22 \\
\hline
\end{tabular}

Three big clusters spanning several areas were significantly more activated by painful compared with nonpainful stimulation in the uncontrollable task and one big cluster for the controllable task (significant on a whole brain-level, voxel-based threshold $Z>2.3$ and cluster-based threshold $p<0.05$ ). Local maxima within the clusters are given for individual anatomical areas. SMA, Supplementary motor cortex; MI, primary motor cortex; ACC, anterior cingulate cortex; SIl, secondary somatosensory cortex; SI, primary somatosensory cortex.

brainstem. The main effects of the uncontrollable warm and controllable warm conditions showed similar, yet less expanded patterns (Fig. 3B). For both tasks, painful stimulation was associated with significantly more activation in pain-processing brain regions than warm stimulation (Table 1 ). This finding was corroborated by testing the correspondence of the experimental conditions with the NPS, a brain system that sensitively scales with perceived pain (Fig. 4A): the NPS response increased significantly for painful compared with warm stimu- lation intensities (main effect "stimulus intensity": $F_{(1,61)}=$ 5.03, $p=0.029$; Fig. $4 B$ ).

\section{Brain activation during uncontrollable stimulation}

The increases in pain perception over the course of a trial in the uncontrollable task were reflected by increasing activation in typical pain-processing regions, including bilateral insula, ACC, bilateral medial thalamus, and pallidum. In addition, activation scaling with intensity ratings was detected in the lateral orbitofrontal cortex (OFC) and occipital lobe (Fig. 5, Table 2). Note that this activation is controlled for activation unrelated to subjective perception by the constant condition regressor.

The GLM was used to contrast brain responses in the uncontrollable and controllable tasks for the painful stimulation, controlling for warm stimulation [contrast (uncontrollable pain $>$ uncontrollable warm) $>$ (controllable pain $>$ controllable warm)], masked with a ROI consisting of pain-processing brain regions. This contrast only revealed activation in SI/primary motor cortex (Table 3). Consistent with this result, the comparison with the NPS did not reveal an interaction between "stimulation intensity," "task" (uncontrollable or controllable), and "regressor type" $\left(F_{(1,62)}=0.52, p=0.473\right)$ nor between "stimulation intensity" and "task" $\left(F_{(1,62)}=0.08, p=0.783\right)$. The results from the NPS and the GLM indicate that the uncontrollable pain condition was not associated with more pain-related activation per se. Importantly, this was also the case when activation related to a constant regressor as well as to a regressor reflecting the increasing pain ratings was taken into account, as evidenced by the nonsignificant interaction for the NPS analysis between "stimulation intensity" and "task."

The PPI demonstrated that, during uncontrollable painful stimulation, connectivity was increased between the anterior insula seed (Fig. 6A) and two clusters in $\mathrm{mPFC}$, one in perigenual ACC (pgACC) $(-10,38,-8, Z=3.22)$ and one in the anteromedial PFC (amPFC) $(8,58,10, Z=3.14$ ) (Fig. $6 B$, Table 4). Neither the amygdala nor the PAG showed significantly increased connectivity with the anterior insula, but 36 contiguous voxels above a voxel-based threshold of $Z=1.6$, uncorrected for spatial extent, were detected in the amygdala (peak: $12,-2,-20, Z=2.72$ ). In the uncontrollable warm condition, increased connectivity of the insula seed with a cluster in dorsal ACC $(8,28,30, Z=3.40)$ was observed (Table $4)$. No increased connectivity was observed with the lateral PFC (hypothesized ROI for controllable task) in the uncontrollable task (painful or warm stimulation intensity). In the "reversed" PPIs of the uncontrollable pain condition with pgACC (Fig. 6C) and amPFC as seeds (Fig. 6D), increased connectivity with the anterior insula, ACC, and inferior parietal lobe was detected (Table 4). In the "reversed" PPI of the 

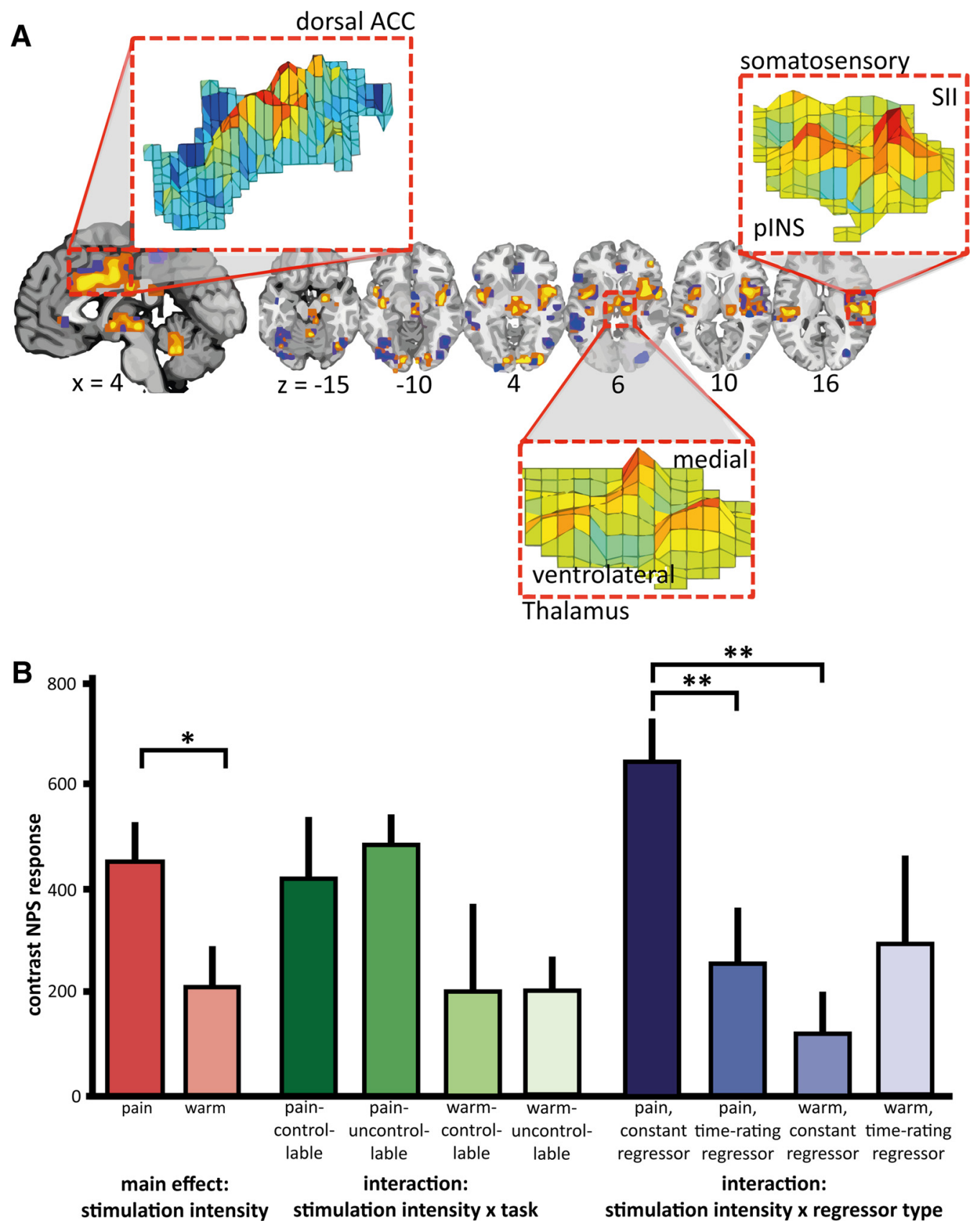

Figure 4. Neurological pain signature (NPS) response. $A$, A priori-defined pattern of the NPS. The insets show examples of the pattern distribution of voxel weights within certain brain areas; ACC, anterior cingulate cortex; SII, secondary somatosensory cortex; pINS, posterior insula. (Figure provided by Dr. Wager, University of Colorado, Boulder, Colorado). B, Estimated values of mixed-model ANOVA analysis of the NPS responses; depicted are post hoc comparisons of the main effect "stimulation intensity" (levels: pain, warm), the interaction "stimulation intensity" $\times$ "task" (levels: controllable, uncontrollable), and the interaction "stimulation intensity" $\times$ "regressor type" (levels: constant, time-rating/temperature). The main effect of "pain" had a significantly higher NPS response than "warm." There was no main effect of "task" $\left(F_{(1,53)}=0.13, p=0.720\right)$, indicating that correspondence to the NPS was comparable for the uncontrollable and controllable tasks. The significant interaction "stimulation intensity" $\times$ "regressor type" with the respective post hoc tests indicates that a higher NPS response was associated with the condition regressors (i.e., constant regressors) compared with the time course regressors of ratings and temperature for painful stimulation. This was not the case for warm stimulation. The nonsignificant interaction "stimulation intensity" $\times$ "task" indicates that the NPS correspondence for pain or warmth was not differentially influenced by un/controllability (post hoc comparison uncontrollable pain versus controllable pain: $p=0.592$ ). Bars represent the mean scalar values expressing the NPS across subjects, error bars the SEM. Scaling of the NPS values depends on many factors such as voxel size, contrast weight, field strength, etc. Because only a within-study comparison was of interest here, we did not attempt to equate scaling of the NPS values with previous studies. ${ }^{*} p<0.05$; ${ }^{* *} p<0.01$.

uncontrollable warm condition with ACC as seed, increased connectivity was detected only with left SI (Table 4).

\section{Brain activation during controllable stimulation}

In the controllable pain condition, activation in pain-processing regions was not correlated with the downregulation of the tem- perature, consistent with the interpretation that subjects successfully kept their sensation constant. The PPI analysis revealed increased inverse connectivity between the anterior insula seed (Fig. $7 A)$ and two clusters in the $\operatorname{dlPFC}(34,58,22 ; Z=3.51 ; 42$, $16,34, Z=3.16$; Fig. $7 B$, Table 4 ) in the painful condition and, partly overlapping, one cluster in the dlPFC in the warm condi- 

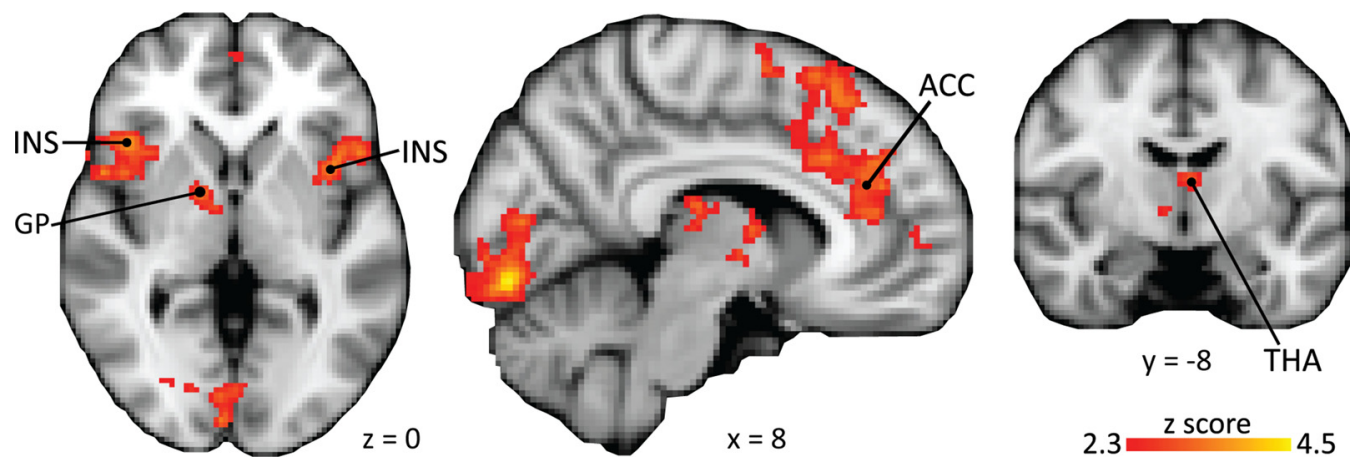

Figure 5. Brain correlates of sensitization in the uncontrollable condition. The subjective ratings in the uncontrollable painful condition correlated with activation in pain-processing areas over and above activation related to the condition. Ins, Insula; GP, globus pallidus; THA, thalamus; ACC, anterior cingulate cortex. For details, see Table 3.

Table 2. Brain activation reflecting the additional sensitization in the uncontrollable pain condition

\begin{tabular}{|c|c|c|c|c|c|}
\hline \multirow[b]{2}{*}{ Brain region } & \multirow{2}{*}{$\begin{array}{l}\text { Cluster size } \\
\text { (no. of voxels) }\end{array}$} & \multirow{2}{*}{$\begin{array}{l}\text { Z-score } \\
\text { peak }\end{array}$} & \multicolumn{3}{|c|}{$\begin{array}{l}\text { MNI peak coordinates } \\
(\mathrm{mm})\end{array}$} \\
\hline & & & $x$ & $y$ & $z$ \\
\hline Cluster spanning & 1446 & 3.61 & 10 & 28 & 50 \\
\hline $\begin{array}{l}\text { Supplementary motor } \\
\text { area }\end{array}$ & & 3.61 & 10 & 28 & 50 \\
\hline $\mathrm{ACC}$ & & $\begin{array}{l}3.59 \\
3.37\end{array}$ & $\begin{array}{r}10 \\
2\end{array}$ & $\begin{array}{l}22 \\
38\end{array}$ & $\begin{array}{l}32 \\
16\end{array}$ \\
\hline Cluster spanning & 1011 & 3.74 & 46 & 20 & -10 \\
\hline OFC & & 3.74 & 46 & 20 & -10 \\
\hline Inferior frontal gyrus & & 3.65 & 50 & 20 & -4 \\
\hline Frontal opercular cortex & & 3.64 & 44 & 20 & 0 \\
\hline $\begin{array}{l}\text { Central opercular cortex } \\
\text { (BA44) }\end{array}$ & & 3.46 & 54 & 8 & 0 \\
\hline Insula & & 3.26 & 44 & 10 & -2 \\
\hline Cluster spanning & 904 & 4.41 & 8 & -84 & -10 \\
\hline Visual cortex & & 4.41 & 8 & -84 & -10 \\
\hline Cluster spanning & 507 & 3.69 & -44 & 16 & -2 \\
\hline Frontal opercular cortex & & 3.69 & -44 & 16 & -2 \\
\hline OFC & & 3.68 & -32 & 20 & -14 \\
\hline Insula & & 3.45 & -38 & 10 & 0 \\
\hline Cluster spanning & 455 & 3.71 & 4 & -2 & 6 \\
\hline Thalamus & & 3.71 & 4 & -2 & 6 \\
\hline Globus pallidus & & 3.34 & 14 & 0 & 2 \\
\hline
\end{tabular}

Listed are brain areas in which activation was significant on a whole-brain level (voxel-based threshold $Z>2.3$ and cluster-based threshold $p<0.05$ ). Please note that local maxima are given as peaks if a significant cluster encompassed more than one region. $A C C$, anterior cingulate cortex; $O F C$, orbitofrontal cortex.

Table 3. Brain activation for the contrast (uncontrollable pain $>$ uncontrollable warm) $>$ (controllable pain $>$ controllable warm)

\begin{tabular}{|c|c|c|c|c|c|}
\hline \multirow[b]{2}{*}{ Brain region } & \multirow{2}{*}{$\begin{array}{l}\text { Cluster size } \\
\text { (no. of voxels) }\end{array}$} & \multirow{2}{*}{$\begin{array}{l}\text { Z-score } \\
\text { peak }\end{array}$} & \multicolumn{3}{|c|}{ MNI peak coordinates $(\mathrm{mm})$} \\
\hline & & & $x$ & $y$ & $z$ \\
\hline Cluster spanning & 1165 & 3.95 & -34 & -26 & 54 \\
\hline Ml & & 3.95 & -34 & -26 & 54 \\
\hline SI & & 3.91 & -38 & -30 & 52 \\
\hline
\end{tabular}

One cluster was significant with a voxel-based threshold $Z>2.3$, cluster-corrected across a mask consisting of pain processing brain regions at $p<0.05$. Local maxima within the cluster are given for individual anatomical areas. MI, primary motor cortex; SI, primary somatosensory cortex.

tion $(34,58,22 ; Z=3.51)$. No significant connectivity was observed with the mPFC, amygdala, and PAG (hypothesized ROIs for uncontrollable task) in the controllable pain or controllable warm conditions. Using dlPFC as seed, the results of the "reversed" PPI analysis for the controllable pain condition revealed increased inverse connectivity with bilateral thalamus $(8,-22$, $16 ; Z=3.87$; Table 4). The "reversed" PPI for the controllable warm condition did not reveal increased connectivity with any region.

\section{Additional analyses}

Repeating the GLM with only the four condition regressors as regressors of interest yielded virtually identical results.

No activation was significantly associated with the time course of the pain ratings in the controllable task (control GLM). Therefore, the additional sensitization appears to be specific for pain in the uncontrollable task.

The GLM and the PPI analyses were repeated including a regressor coding for the button presses. The GLM results were similar to the original analysis, albeit partly at a lower statistical threshold. The PPI results were only slightly different with the main difference that the anterior insula seed did no longer show significant inverse connectivity with the dIPFC in the controllable warm condition when the button presses were included.

The time courses of signal change in the anterior insula further support the picture gleaned from the GLM analysis as well as the comparison with the NPS: the constant regressors for uncontrollable pain and controllable pain and the time-intensity curve for uncontrollable pain were best reflected by the signal change in the insula. The two warm conditions (uncontrollable and controllable) were also well reflected but showed lower percentage signal changes (Fig. 8).

\section{Discussion}

Here, we identify brain regions important for driving pain facilitation by uncontrollability and suggest mechanisms by which pain is facilitated or inhibited when stimulation is uncontrollable or controllable. We show that uncontrollable pain is associated with increased sensitization, reflected by increased activation in pain-processing regions. At the same time, uncontrollable pain was not associated with a higher activation magnitude in painprocessing regions compared with controllable pain, as investigated with univariate GLM analysis as well as by comparison with the NPS, a multivariate pain activation pattern. Rather, uncontrollability-induced pain facilitation increased the connectivity of $\mathrm{mPFC}$ with anterior insula, ACC, and the inferior parietal lobe. Anterior insula and ACC are important pain-processing areas and the connectivity to the inferior parietal lobe might include SII, which is also involved in pain processing. There was some indication of increased coupling between the dorsal ACC and insula and/or SI for the uncontrollable warm condition. Although this indicates that the role of the mPFC in the context of stimulus uncontrollability might not be specific to pain, it should be noted that the dorsal ACC does not belong to the mPFC regions previously implicated in pain facilitation by negative emotions (Ploghaus et al., 2001; Schweinhardt et al., 2008; Berna et al., 2010). Consistent with this, we observed behavioral conse- 
A

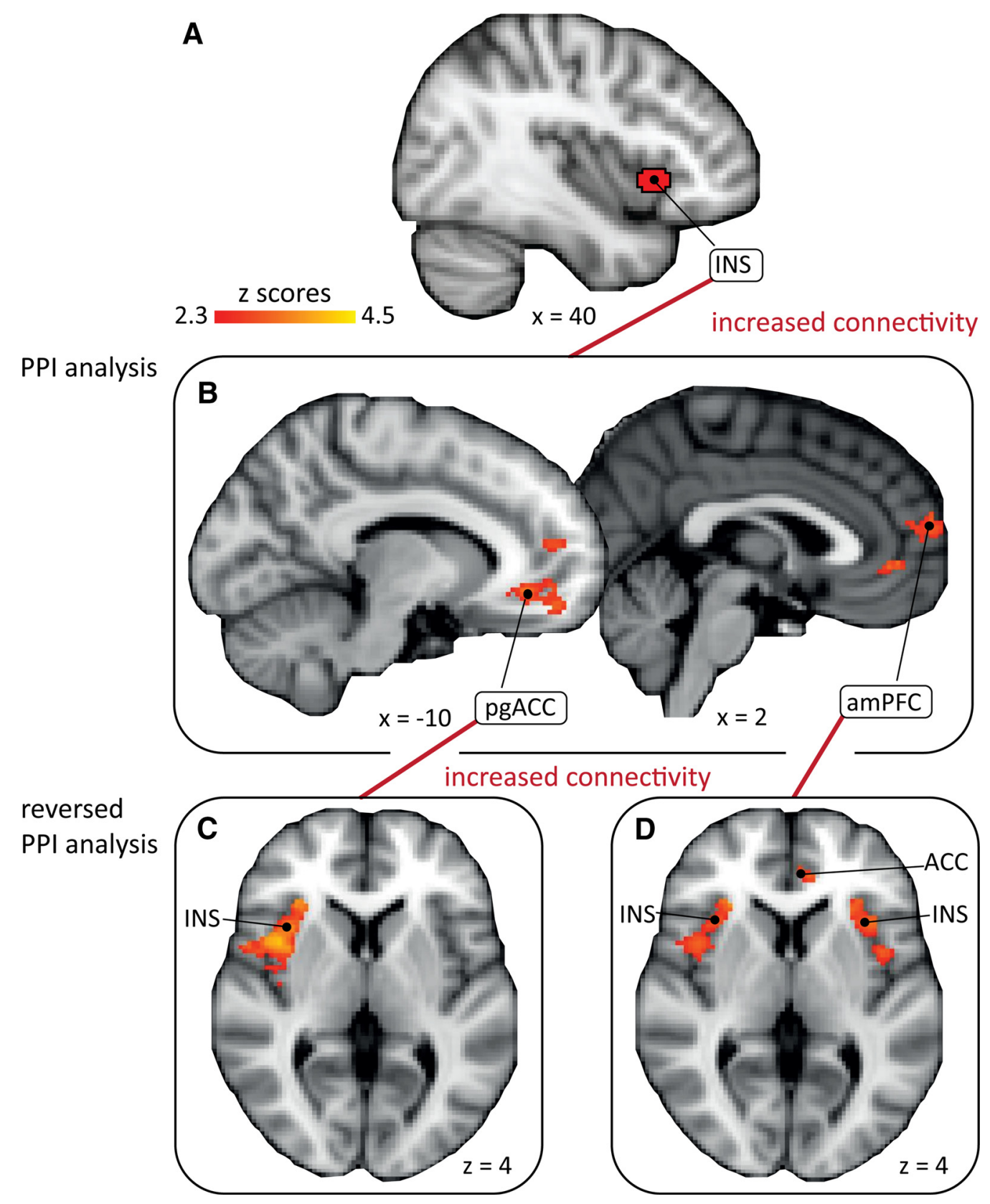

Figure 6. Connectivity between insula and medial PFC and connectivity between medial PFC and pain-processing regions. The PPI analysis shows that the connectivity of the anterior insula as seed $(\boldsymbol{A})$ is increased during uncontrollable painful stimulation with two clusters in $\mathrm{mPFC}$ (pgACC and amPFC) $(\boldsymbol{B})$. The "reverse" PPl analyses with pgACC and amPFC (B) as seeds show increased connectivity with right anterior insula and inferior parietal lobe (seed: $\mathrm{pgACC})(\boldsymbol{C}$; inferior parietal lobe not depicted) and with the bilateral anterior insula and $\mathrm{ACC}($ seed: amPFC) $(\boldsymbol{D})$ during uncontrollable painful stimulation. For details, see Table 4. INS, insula; PgACC, perigenual anterior cingulate cortex; amPFC, anteromedial prefrontal cortex.

quences (i.e., increased sensitization) of uncontrollability only for painful stimulation. The amygdala appeared to contribute to uncontrollability-induced pain facilitation, but only at a lenient statistical threshold. We also confirmed the dlPFC as being an important region for the pain-inhibitory effects of controllability and present data suggesting that this inhibition is achieved by increased inverse connectivity of the dlPFC with the anterior insula and thalamus during controllable pain stimulation.

\section{Dissociation of pain perception in controllable and uncontrollable tasks}

During painful trials in the controllable task, subjects showed sensitization as a specific form of pain facilitation indexed by downregulation of the temperature. Such sensitization has been shown before in similar paradigms (Kleinböhl et al., 1999; Hölzl et al., 2005; Becker et al., 2011) and related to spinal wind-up (Eide, 2000; Kleinböhl et al., 2006). Subjects with a high external locus of control showed more temperature downregulation with controllable pain, in accordance with theories of learned helplessness (Abramson et al., 1978; Müller, 2012).

Sensitization with controllable pain was not significantly associated with increased activation in any pain-processing area, consistent with the notion that it does not involve supraspinal mechanisms. In the uncontrollable task, the same nociceptive inputs were reapplied, thereby accounting for peripheral and spinal sensitization. Now, these temperature profiles were consistently 
Table 4. Functional connectivity of the anterior insula with regions of interest during uncontrollable and controllable stimulation and of the "reversed" analyses based on the prior results

\begin{tabular}{|c|c|c|c|c|c|c|}
\hline \multirow[b]{2}{*}{ Brain region } & \multirow[b]{2}{*}{ Cluster size (no. of voxels) } & \multirow[b]{2}{*}{ Connectivity } & \multirow[b]{2}{*}{ Z-score peak } & \multicolumn{3}{|c|}{ MNI peak coordinates (mm) } \\
\hline & & & & $x$ & $y$ & $z$ \\
\hline \multicolumn{7}{|l|}{ Uncontrollable pain; insula seed } \\
\hline Perigenual ACC & 243 & Positive & 3.22 & -10 & 38 & -8 \\
\hline \multicolumn{7}{|c|}{ Uncontrollable pain; amPFC seed ("reversed" PPI) } \\
\hline $\mathrm{pgACC} /$ dorsal ACC & 577 & Positive & 3.57 & 2 & 40 & 14 \\
\hline Insula/frontal operculum & 408 & Positive & 3.91 & -34 & 18 & 8 \\
\hline Insula/frontal operculum & 775 & Positive & 4.09 & 36 & 12 & 14 \\
\hline Inferior parietal lobule & 212 & Positive & 4.01 & 62 & -32 & 36 \\
\hline \multicolumn{7}{|c|}{ Uncontrollable warm; insula seed } \\
\hline $\mathrm{ACC}$ & 181 & Positive & 3.40 & 8 & 28 & 30 \\
\hline \multicolumn{7}{|c|}{ Uncontrollable warm; ACC seed ("reversed" PPI) } \\
\hline SI/postcentral gyrus & 363 & Positive & 3.91 & -32 & -36 & 40 \\
\hline Thalamus & 888 & Negative & 3.87 & 8 & -22 & 16 \\
\hline \multicolumn{7}{|l|}{ Controllable warm; insula (seed) } \\
\hline dIPFC & 200 & Negative & 3.51 & 34 & 58 & 22 \\
\hline
\end{tabular}

Listed are brain areas in which functional connectivity was significant on a voxel-based threshold of $Z>2.3$, corrected for spatial extent across ROIs at a cluster level of $p<0.05$. The ROIs for the PPI analysis with the insula seed were medial PFC, amygdala, PAG, and dIPFC. The ROIs for the "reversed" PPIs consisted of pain-processing brain regions. amPFC, anteromedial prefrontal cortex; ACC, anterior cingulate cortex; PgACC, perigenual ACC; SI, primary somatosensory cortex; dIPFC, dorsolateral prefrontal cortex.

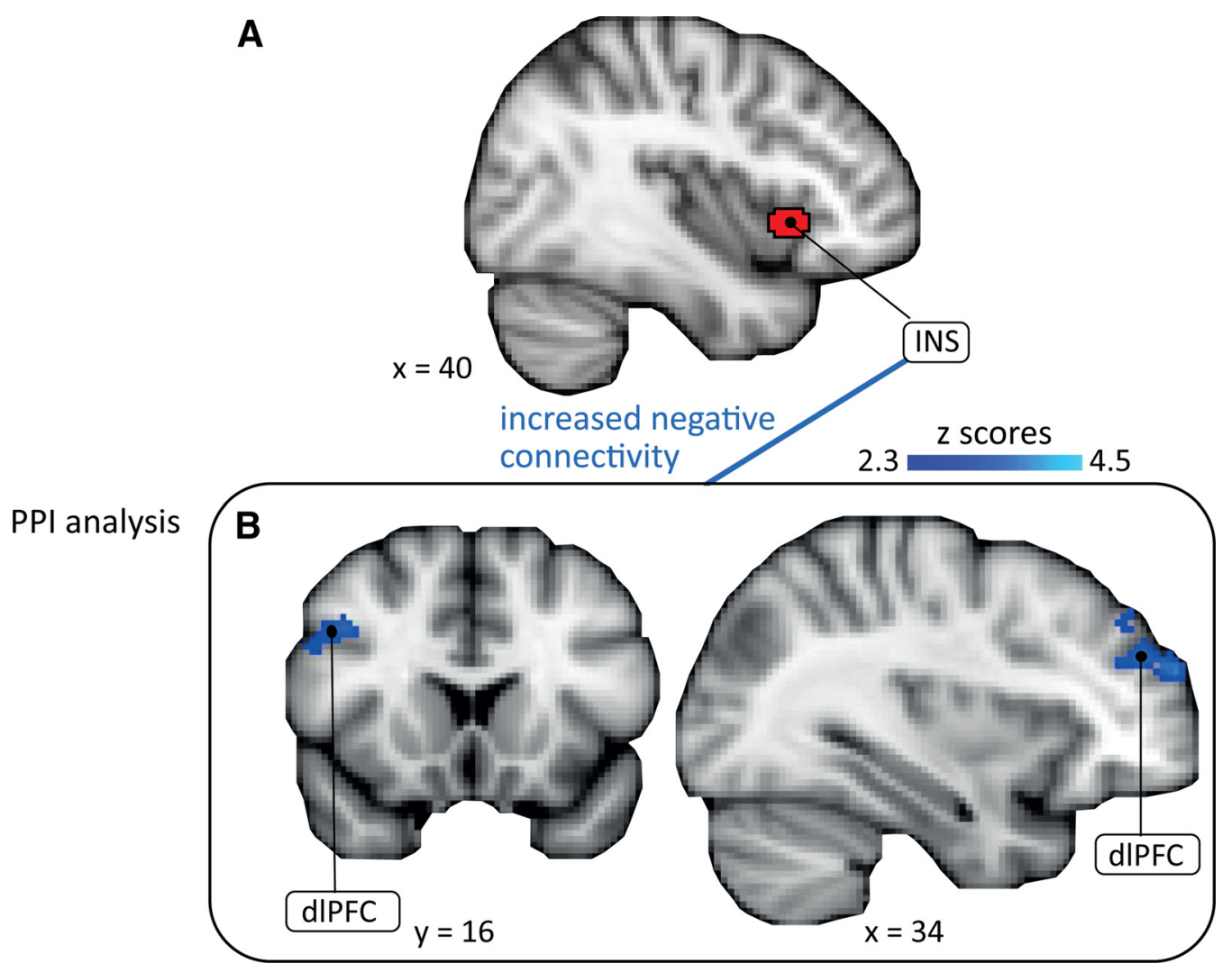

Figure 7. Connectivity between insula and dIPFC. The PPI analysis shows that the inverse connectivity of the anterior insula (seed; $\boldsymbol{A}$ ) with two clusters in the dIPFC ( $\boldsymbol{B}$ ) is increased during controllable painful stimulation. INS, insula; dIPFC, dorsolateral prefrontal cortex.

rated as increasingly painful over the course of the individual trials, demonstrating the pain-facilitatory effects of uncontrollability. Previous imaging studies of uncontrollable pain have largely failed to demonstrate behavioral pain-increasing effects of uncontrollability (but see Wiech et al., 2006).
Uncontrollability leads to increased activation in painprocessing brain regions and $\mathrm{OFC}$

Insula, ACC, medial thalamus, and pallidum encoded sensitization during uncontrollable pain, confirming indirect evidence from earlier studies that used uncontrollable pain stimulation as 


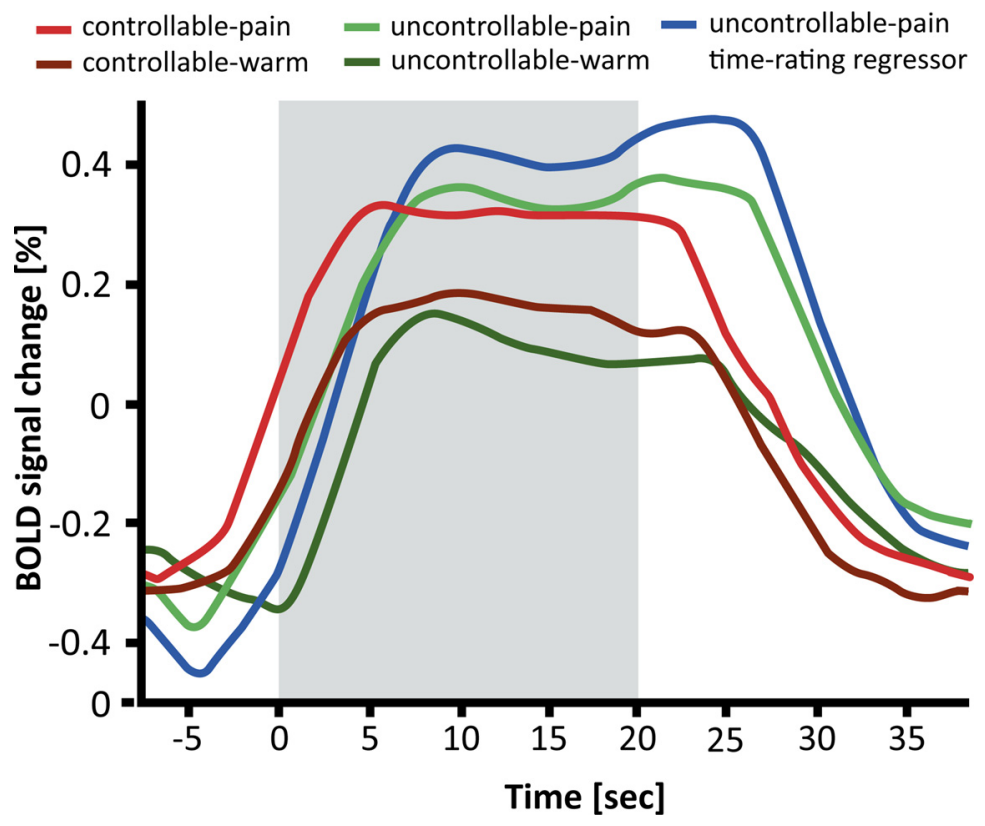

Figure 8. Time courses of BOLD signal change in the anterior insula. Modeled time courses for the conditions controllable pain, uncontrollable pain, controllable warm, uncontrollable warm, and the uncontrollable pain time-rating regressor from the anterior insula; shaded area: stimulation interval after the target temperature was reached. Percentage signal change was calculated relative to the mean of each time series.

a control condition (Salomons et al., 2004; Mohr et al., 2005; Wiech et al., 2006). Each of these regions contains nociceptive neurons encoding stimulus intensity (Kenshalo et al., 1980; Sikes and Vogt, 1992; Chudler and Dong, 1995; Frot et al., 2007). The signal in these regions scales linearly with the perceived intensity of different stimulus intensities in brain-imaging studies (Coghill et al., 1999; Seminowicz and Davis, 2007; Loggia et al., 2012), although nonlinear relationships between applied intensity and BOLD response have been observed (Johnstone et al., 2012). Therefore, the result that the additional sensitization in uncontrollable pain scales with the activation in these regions (compared with controllable pain) indicates that the loss of control leads to amplified processing of the nociceptive input.

The lateral OFC also showed increased activation with sensitization during uncontrollable pain. This is not a typical painencoding region, but has been associated with uncontrollable (Wiech et al., 2006) as well as unpredictable (Carlsson et al., 2006) pain and the fear of pain (Ochsner et al., 2006). Because the lateral OFC is implicated in the processing of punishers (O'Doherty et al., 2001), its activation in the present study may reflect negative affective processing induced by uncontrollable pain.

\section{mPFC might drive additional sensitization during uncontrollable pain stimulation}

Our results suggest brain regions that mediate pain facilitation during uncontrollable stimulation, namely pgACC and amPFC as parts of the mPFC. In demonstrating stronger coupling of $\mathrm{mPFC}$ to the anterior insula, ACC, and inferior parietal lobe during uncontrollable pain, we extend previous work that observed increased activation in these regions during uncontrollable compared with controllable painful stimulation (Salomons et al., 2004; Wiech et al., 2006). Our results link the activity to behavioral pain facilitation and suggest that the mPFC drives the additional sensitization, perhaps via direct connections to the pain-processing regions anterior insula and ACC (Mesulam and Mufson, 1982; Mufson and Mesulam, 1982). The mPFC is sug- gested to play a major role in emotional processing, with regulatory functions of the perigenual and subgenual ACC and mPFC especially for negative emotions (Etkin et al., 2011). Regarding pain, $\mathrm{mPFC}$ has been shown to mediate pain facilitation by negative emotions (Ploghaus et al., 2001; Schweinhardt et al., 2008; Berna et al., 2010). In subacute back pain patients, increased functional connectivity between $\mathrm{MPFC}$ and nucleus accumbens predicted transition to chronic pain (Baliki et al., 2012), suggesting the clinical significance of this region. Because the MPFC is a large area, the question arises whether different subregions assume different pain-facilitatory roles. The studies discussed above have either described relevant activation in perigenual or subgenual ACC (Ploghaus et al., 2001; Berna et al., 2010) or the amPFC (Schweinhardt et al., 2008; Baliki et al., 2012), the latter being two patient studies. Interestingly, here, both pgACC and amPFC showed increased connectivity with the anterior insula during uncontrollable pain. It seems important to probe specific $\mathrm{mPFC}$ subregions in future studies of pain facilitation.

Although below the significance threshold, the amygdala also showed stronger coupling to the anterior insula during uncontrollable pain, consistent with the notion that a lack of control increases the threatening value of pain (Bowers, 1968; Arntz and Schmidt, 1989). Contrary to our hypothesis, PAG did not contribute to pain facilitation. This might indicate that pain facilitation by uncontrollability is not mediated via descending pathways, in contrast to many pain-inhibitory processes (Basbaum and Fields, 1984). However, negative findings of course need to be interpreted with caution.

\section{dlPFC might mediate controllability-induced pain inhibition}

We confirmed dlPFC activation during controllable pain, consistent with a previous study on pain controllability (Wiech et al., 2006) and other forms of cognitive-emotional hypoalgesia (Wager et al., 2004). Furthermore, our study showed an increased inverse connectivity between insula and dlPFC and between dlPFC and thalamus during controllable pain. This means that, as activity in the dlPFC increases, activity in the insula and thalamus decreases. Interestingly, although the anterior insula was inversely connected to the dlPFC also during controllable warm stimulation, the "reversed PPI" with a dlPFC seed did not reveal any significantly connected regions for the controllable warm condition. Therefore, it appears that downregulation of regions processing pain and warmth occurs predominantly with painful stimulation. Animal studies provide further insight into possible mechanisms by showing that having control is conveyed via signaling from vmPFC, the homologous region in the rat to the human dlPFC (Uylings et al., 2003), to the dorsal raphe nucleus. During controllable stress, stress-induced activation of the dorsal raphe nucleus is inhibited by the vmPFC and behavioral consequences of uncontrollable stress (potentiated fear conditioning, escape deficits) are blocked, which is reversed by pharmacological inactivation of vmPFC (Amat et al., 2005). 


\section{Clinical implications}

Chronic pain is in many instances uncontrollable. Experiencing uncontrollable pain can lead to hypervigilance (Aldrich et al., 2000), learned helplessness, and depression, resulting in a selfamplifying vicious circle (Arntz and Schmidt, 1989). Further, losing control over pain potentially increases fear of pain and interferes with task performance (Crombez et al., 2008). In contrast, perceived control decreases pain and discomfort in acute pain (Thrash et al., 1982) and is associated with better functioning in chronic pain patients (Tan et al., 2002). Understanding the endogenous mechanisms underlying pain modulation by uncontrollability and controllability might inform clinical approaches of pain management and therapy. Further, the brain regions that drive pain facilitation or inhibition by uncontrollability or controllability could be targeted with methods such as transmagnetic stimulation or neurofeedback with the aim to reduce clinical pain.

The finding that the perceptual sensitization induced by uncontrollability was not reflected by a higher activation magnitude in pain-processing regions indicates that a lot has to be learned about pain processing in the brain before pain biomarkers based on activation patters should be considered (Davis et al., 2012). In particular, it needs to be established whether different types of pain augmentation and facilitation (e.g., by increased nociceptive input or different types of cognitive-emotional pain modulation) are associated with consistent (connectivity) patterns in the brain or if the brain can construct the sensation of "pain" via different mechanisms.

\section{References}

Abramson LY, Seligman ME, Teasdale JD (1978) Learned helplessness in humans: critique and reformulation. J Abnorm Psychol 87:49-74. CrossRef Medline

Aldrich S, Eccleston C, Crombez G (2000) Worrying about chronic pain: vigilance to threat and misdirected problem solving. Behav Res Ther 38: 457-470. CrossRef Medline

Amat J, Baratta MV, Paul E, Bland ST, Watkins LR, Maier SF (2005) Medial prefrontal cortex determines how stressor controllability affects behavior and dorsal raphe nucleus. Nat Neurosci 8:365-371. CrossRef Medline

Apkarian AV, Bushnell MC, Treede RD, Zubieta JK (2005) Human brain mechanisms of pain perception and regulation in health and disease. Eur J Pain 9:463-484. CrossRef Medline

Arntz C, Schmidt A (1989) Perceived control and the experience of pain. In: Stress, personal control and health (Steptoe A, Appels A, eds), pp 131-162. Brussels: Wiley.

Baliki MN, Petre B, Torbey S, Herrmann KM, Huang L, Schnitzer TJ, Fields HL, Apkarian AV (2012) Corticostriatal functional connectivity predicts transition to chronic back pain. Nat Neurosci 15:1117-1119. CrossRef Medline

Basbaum AI, Fields HL (1984) Endogenous pain control systems: brainstem spinal pathways and endorphin circuitry. Annu Rev Neurosci 7:309-338. CrossRef Medline

Becker S, Kleinböhl D, Baus D, Hölzl R (2011) Operant learning of perceptual sensitization and habituation is impaired in fibromyalgia patients with and without irritable bowel syndrome. Pain 152:1408-1417. CrossRef Medline

Beckmann CF, Smith SM (2004) Probabilistic independent component analysis for functional magnetic resonance imaging. IEEE Trans Med Imaging 23:137-152. CrossRef Medline

Beckmann CF, Jenkinson M, Smith SM (2003) General multilevel linear modeling for group analysis in FMRI. Neuroimage 20:1052-1063. CrossRef Medline

Berna C, Leknes S, Holmes EA, Edwards RR, Goodwin GM, Tracey I (2010) Induction of depressed mood disrupts emotion regulation neurocircuitry and enhances pain unpleasantness. Biol Psychiatry 67:1083-1090. CrossRef Medline

Biswal BB, Mennes M, Zuo XN, Gohel S, Kelly C, Smith SM, Beckmann CF, Adelstein JS, Buckner RL, Colcombe S, Dogonowski AM, Ernst M, Fair D, Hampson M, Hoptman MJ, Hyde JS, Kiviniemi VJ, Kötter R, Li SJ, Lin
CP, et al. (2010) Toward discovery science of human brain function. Proc Natl Acad Sci U S A 107:4734-4739. CrossRef Medline

Borckardt JJ, Reeves ST, Frohman H, Madan A, Jensen MP, Patterson D, Barth K, Smith AR, Gracely R, George MS (2011) Fast left prefrontal rTMS acutely suppresses analgesic effects of perceived controllability on the emotional component of pain experience. Pain 152:182-187. CrossRef Medline

Bowers KS (1968) Pain, anxiety, and perceived control. J Consult Clin Psychol 32:596-602. CrossRef Medline

Carlsson K, Andersson J, Petrovic P, Petersson KM, Ohman A, Ingvar M (2006) Predictability modulates the affective and sensory-discriminative neural processing of pain. Neuroimage 32:1804-1814. CrossRef Medline

Chudler EH, Dong WK (1995) The role of the basal ganglia in nociception and pain. Pain 60:3-38. CrossRef Medline

Coghill RC, Sang CN, Maisog JM, Iadarola MJ (1999) Pain intensity processing within the human brain: a bilateral, distributed mechanism. J Neurophysiol 82:1934-1943. Medline

Crombez G, Eccleston C, De Vlieger P, Van Damme S, De Clercq A (2008) Is it better to have controlled and lost than never to have controlled at all? An experimental investigation of control over pain. Pain 137:631-639. CrossRef Medline

Davis KD, Racine E, Collett B (2012) Neuroethical issues related to the use of brain imaging: can we and should we use brain imaging as a biomarker to diagnose chronic pain? Pain 153:1555-1559. CrossRef Medline

Eide PK (2000) Wind-up and the NMDA receptor complex from a clinical perspective. Eur J Pain 4:5-15. CrossRef Medline

Etkin A, Egner T, Kalisch R (2011) Emotional processing in anterior cingulate and medial prefrontal cortex. Trends Cogn Sci 15:85-93. CrossRef Medline

Farrell MJ, Laird AR, Egan GF (2005) Brain activity associated with painfully hot stimuli applied to the upper limb: a meta-analysis. Hum Brain Mapp 25:129-139. CrossRef Medline

Friston KJ, Buechel C, Fink GR, Morris J, Rolls E, Dolan RJ (1997) Psychophysiological and modulatory interactions in neuroimaging. Neuroimage 6:218-229. CrossRef Medline

Frot M, Magnin M, Mauguière F, Garcia-Larrea L (2007) Human SII and posterior insula differently encode thermal laser stimuli. Cereb Cortex 17:610-620. Medline

Gwilym SE, Keltner JR, Warnaby CE, Carr AJ, Chizh B, Chessell I, Tracey I (2009) Psychophysical and functional imaging evidence supporting the presence of central sensitization in a cohort of osteoarthritis patients. Arthritis Rheum 61:1226-1234. CrossRef Medline

Härkäpää K, Järvikoski A, Mellin G, Hurri H, Luoma J (1991) Health locus of control beliefs and psychological distress as predictors for treatment outcome in low-back pain patients: Results of a 3-month follow-up of a controlled intervention study. Pain 46:35-41. CrossRef Medline

Helmchen C, Mohr C, Erdmann C, Binkofski F, Büchel C (2006) Neural activity related to self-versus externally generated painful stimuli reveals distinct differences in the lateral pain system in a parametric fMRI study. Hum Brain Mapp 27:755-765. CrossRef Medline

Hölzl R, Kleinböhl D, Huse E (2005) Implicit operant learning of pain sensitization. Pain 115:12-20. CrossRef Medline

Jenkinson M, Bannister P, Brady M, Smith S (2002) Improved optimization for the robust and accurate linear registration and motion correction of brain images. Neuroimage 17:825-841. CrossRef Medline

Jensen MP, Karoly P (1991) Control beliefs, coping efforts, and adjustment to chronic pain. J Consult Clin Psychol 59:431-438. CrossRef Medline

Johnstone T, Salomons TV, Backonja MM, Davidson RJ (2012) Turning on the alarm: The neural mechanisms of the transition from innocuous to painful sensation. Neuroimage 59:1594-1601. CrossRef Medline

Kates WR, Frederikse M, Mostofsky SH, Folley BS, Cooper K, MazurHopkins P, Kofman O, Singer HS, Denckla MB, Pearlson GD, Kaufmann WE (2002) MRI parcellation of the frontal lobe in boys with attention deficit hyperactivity disorder or Tourette syndrome. Psychiatry Res 116: 63-81. CrossRef Medline

Kenshalo DR Jr, Giesler GJ Jr, Leonard RB, Willis WD (1980) Responses of neurons in primate ventral posterior lateral nucleus to noxious stimuli. J Neurophysiol 43:1594-1614. Medline

Kleinböhl D, Hölzl R, Möltner A, Rommel C, Weber C, Osswald PM (1999) Psychophysical measures of sensitization to tonic heat discriminate chronic pain patients. Pain 81:35-43. CrossRef Medline

Kleinböhl D, Trojan J, Konrad C, Hölzl R (2006) Sensitization and habitu- 
ation of AMH and C-fiber related percepts of repetitive radiant heat stimulation. Clin Neurophysiol 117:118-130. Medline

Lautenbacher S, Möltner A, Strain F (1992) Psychophysical features of the transition from pure heat perception to heat pain perception. Percept Psychophys 52:685-690. CrossRef Medline

Levenson H (1981) Differentiating among internality, powerful others, and chance. In: Research with the locus of control construct, Vol 1, Assessment methods (HM Lefcourt, ed), pp 15-63. New York: Academic.

Loggia ML, Edwards RR, Kim J, Vangel MG, Wasan AD, Gollub RL, Harris RE, Park K, Napadow V (2012) Disentangling linear and nonlinear brain responses to evoked deep tissue pain. Pain 153:2140-2151. CrossRef Medline

Mayer EA, Berman S, Suyenobu B, Labus J, Mandelkern MA, Naliboff BD, Chang L (2005) Differences in brain responses to visceral pain between patients with irritable bowel syndrome and ulcerative colitis. Pain 115: 398-409. CrossRef Medline

McLaren DG, Ries ML, Xu G, Johnson SC (2012) A generalized form of contextdependent psychophysiological interactions (gPPI): a comparison to standard approaches. Neuroimage 61:1277-1286. CrossRef Medline

Mesulam MM, Mufson EJ (1982) Insula of the old world monkey. III: Efferent cortical output and comments on function. J Comp Neurol 212: 38-52. CrossRef Medline

Miller SM (1979) Controllability and human stress: method, evidence and theory. Behav Res Ther 17:287-304. CrossRef Medline

Mohr C, Binkofski F, Erdmann C, Büchel C, Helmchen C (2005) The anterior cingulate cortex contains distinct areas dissociating external from self-administered painful stimulation: a parametric fMRI study. Pain 114: 347-357. CrossRef Medline

Mufson EJ, Mesulam MM (1982) Insula of the old world monkey. II: Afferent cortical input and comments on the claustrum. J Comp Neurol 212: 23-37. CrossRef Medline

Müller MJ (2011) Helplessness and perceived pain intensity: relations to cortisol concentrations after electrocutaneous stimulation in healthy young men. Biopsychosoc Med 5:8. CrossRef Medline

Müller MJ (2012) Will it hurt less if I believe I can control it? Influence of actual and perceived control on perceived pain intensity in healthy male individuals: a randomized controlled study. J Behav Med 35:529-537. CrossRef Medline

Neugebauer V, Li W, Bird GC, Han JS (2004) The amygdala and persistent pain. Neuroscientist 10:221-234. CrossRef Medline

Ochsner KN, Ludlow DH, Knierim K, Hanelin J, Ramachandran T, Glover GC, Mackey SC (2006) Neural correlates of individual differences in pain-related fear and anxiety. Pain 120:69-77. CrossRef Medline

O’Doherty J, Kringelbach ML, Rolls ET, Hornak J, Andrews C (2001) Abstract reward and punishment representations in the human orbitofrontal cortex. Nat Neurosci 4:95-102. CrossRef Medline

O'Reilly JX, Woolrich MW, Behrens TE, Smith SM, Johansen-Berg H (2012) Tools of the trade: psychophysiological interactions and functional connectivity. Soc Cogn Affect Neurosci 7:604-609. CrossRef Medline

Phelps EA, LeDoux JE (2005) Contributions of the amygdala to emotion processing: from animal models to human behavior. Neuron 48:175-187. CrossRef Medline

Ploghaus A, Narain C, Beckmann CF, Clare S, Bantick S, Wise R, Matthews PM, Rawlins JN, Tracey I (2001) Exacerbation of pain by anxiety is associated with activity in a hippocampal network. J Neurosci 21:9896-9903. Medline

Porreca F, Ossipov MH, Gebhart GF (2002) Chronic pain and medullary descending facilitation. Trends Neurosci 25:319-325. CrossRef Medline

Rolke R, Baron R, Maier C, Tölle TR, Treede RD, Beyer A, Binder A,
Birbaumer N, Birklein F, Bötefür IC, Braune S, Flor H, Huge V, Klug R, Landwehrmeyer GB, Magerl W, Maihöfner C, Rolko C, Schaub C, Scherens A, et al. (2006) Quantitative sensory testing in the German Research Network on Neuropathic Pain (DFNS): standardized protocol and reference values. Pain 123:231-243. CrossRef Medline

Salomons TV, Johnstone T, Backonja MM, Davidson RJ (2004) Perceived controllability modulates the neural response to pain. J Neurosci 24: 7199-7203. CrossRef Medline

Salomons TV, Johnstone T, Backonja MM, Shackman AJ, Davidson RJ (2007) Individual differences in the effects of perceived controllability on pain perception: critical role of the prefrontal cortex. J Cogn Neurosci 19:993-1003. CrossRef Medline

Schweinhardt P, Kalk N, Wartolowska K, Chessell I, Wordsworth P, Tracey I (2008) Investigation into the neural correlates of emotional augmentation of clinical pain. Neuroimage 40:759-766. CrossRef Medline

Seminowicz DA, Davis KD (2007) Interactions of pain intensity and cognitive load: the brain stays on task. Cereb Cortex 17:1412-1422. CrossRef Medline

Sikes RW, Vogt BA (1992) Nociceptive neurons in area 24 of rabbit cingulate cortex. J Neurophysiol 68:1720-1732. Medline

Smith SM, Jenkinson M, Woolrich MW, Beckmann CF, Behrens TE, Johansen-Berg H, Bannister PR, De Luca M, Drobnjak I, Flitney DE, Niazy RK, Saunders J, Vickers J, Zhang Y, De Stefano N, Brady JM, Matthews PM (2004) Advances in functional and structural MR image analysis and implementation as FSL. Neuroimage 23:S208-S219. CrossRef Medline

Spielberger R, Gorsuch R, Lushene R (1970) STAI manual for the StateTrait Anxiety Inventory 1970. Palo Alto, CA: Consulting Psychologists.

Tan G, Jensen MP, Robinson-Whelen S, Thornby JI, Monga T (2002) Measuring control appraisals in chronic pain. J Pain 3:385-393. CrossRef Medline

Thrash WJ, Marr JN, Box TG (1982) Effects of continuous patient information in the dental environment. J Dent Res 61:1063-1065. CrossRef Medline

Tinti C, Schmidt S, Businaro N (2011) Pain and emotions reported after childbirth and recalled 6 months later: the role of controllability. J Psychosom Obstet Gynaecol 32:98-103. CrossRef Medline

Uylings HB, Groenewegen HJ, Kolb B (2003) Do rats have a prefrontal cortex? Behav Brain Res 146:3-17. CrossRef Medline

Wager TD, Rilling JK, Smith EE, Sokolik A, Casey KL, Davidson RJ, Kosslyn SM, Rose RM, Cohen JD (2004) Placebo-induced changes in FMRI in the anticipation and experience of pain. Science 303:1162-1167. CrossRef Medline

Wager TD, Atlas LY, Lindquist MA, Roy M, Woo CW, Kross E (2013) An fMRI-based neurologic signature of physical pain. N Engl J Med 368: 1388-1397. CrossRef Medline

Wiech K, Kalisch R, Weiskopf N, Pleger B, Stephan KE, Dolan RJ (2006) Anterolateral prefrontal cortex mediates the analgesic effect of expected and perceived control over pain. J Neurosci 26:11501-11509. CrossRef Medline

Yoshida W, Seymour B, Koltzenburg M, Dolan RJ (2013) Uncertainty increases pain: evidence for a novel mechanism of pain modulation involving the periaqueductal gray. J Neurosci 33:5638-5646. CrossRef Medline

Zhang Y, Brady M, Smith S (2001) Segmentation of brain MR images through a hidden Markov random field model and the expectationmaximization algorithm. IEEE Trans Med Imaging 20:45-57. CrossRef Medline 